\title{
A Form of Inherited Cerebellar Ataxia with Saccadic Intrusions, Increased Saccadic Speed, Sensory Neuropathy, and Myoclonus
}

\author{
BARBARA E. SWARTZ,${ }^{a}$ MARGIT BURMEISTER,${ }^{b}$ JEFFREY T. SOMERS,${ }^{c}$ \\ KLAUS G. ROTTACH,${ }^{d}$ IRINA N. BESPALOVA, ${ }^{b}$ AND R. JOHN LEIGH ${ }^{a}$ \\ ${ }^{a}$ Veterans' Affairs Medical Center and Case Western University, \\ Cleveland 44106, Ohio, USA \\ ${ }^{b}$ University of Michigan, Ann Arbor, Michigan, USA \\ ' Johnson Space Center, Houston, Texas, USA \\ d87600 Kaufbeuren, Germany
}

KEYwORDS: cerebellum; ataxia; saccades

Over the past five years, rapid progress has been made in genetically identifying different forms of spinocerebellar atrophy (SCA), for which several characteristic disorders of eye movements have been reported. ${ }^{1,2}$ Nonetheless, the genetic disorder in some families has not yet been discovered, and this report concerns one such kinship. We studied a family of Slovenian descent in which 5 of 14 siblings presented with progressive ataxia. Two other siblings, who we did not study, may also show involvement, but neither parent and none of 27 children of the 14 siblings has been affected. We examined the five definitely affected patients several times over a 5year period; electroencephalography, electromyography, and MRI brain imaging were performed. In Patient 5 (the proband), we carried out genetic screening (Athena Laboratories) for Friedreich's ataxia, spinocerebellar ataxia (SCA) 1-3 and 6-8, and Unverricht-Lundborg progressive myoclonic epilepsy (EMP1). We compared results of eye movement studies with a group of 10 normal subjects ( 2 female; median age 40 years, range 23-60). We measured horizontal and vertical eye movements using the magnetic search coil technique. We tested fixation, horizontal and vertical saccades, smooth pursuit, and vestibulo-ocular reflex (VOR), and vergence, as previously described. ${ }^{3,4}$ All patients and subjects gave informed, written consent, as approved by our Institutional Review Board.

Clinical findings of the five affected sibs that we studied are summarized in TABLE 1. Disease onset was insidious; early symptoms could be remembered by all sibs during their early twenties, consisting of gait unsteadiness and difficulty read-

Address for correspondence: Barbara A. Swartz, M.D., Ph.D., Department of Neurology, University Hospitals of Cleveland, 11100 Euclid Avenue, Cleveland, OH 44106. Voice: 216-8443714; fax: 216-844-5066.

Barbara.Swartz@uhhs.com

Ann. N.Y. Acad. Sci. 956: 441-444 (2002). () 2002 New York Academy of Sciences. 
TABLE 1. Summary of clinical findings

\begin{tabular}{lcccccccc}
\hline Case/Sex & Age & Ataxia & $\begin{array}{c}\text { Saccadic } \\
\text { intrusions }\end{array}$ & $\begin{array}{c}\text { UMN } \\
\text { signs }\end{array}$ & $\begin{array}{c}\text { LMN } \\
\text { signs }\end{array}$ & $\begin{array}{c}\text { Sensory } \\
\text { loss }\end{array}$ & Disability Myoclonus \\
\hline 1/M & $54 / 39$ & +++ & $1.8 / \mathrm{s}$ & ++ & ++ & ++ & +++ & + \\
$2 / \mathrm{M}$ & $52 / 36$ & ++ & $3.1 / \mathrm{s}$ & + & + & ++ & ++ & + \\
$3 / \mathrm{F}$ & $50 / 28$ & +++ & $2.4 / \mathrm{s}$ & + & + & + & +++ & + \\
$4-\mathrm{P} / \mathrm{M}$ & $49 / 23$ & ++ & $3.1 / \mathrm{s}$ & + & + & ++ & ++ & + \\
$5 / \mathrm{M}$ & $47 / 34$ & + & $2.0 / \mathrm{s}$ & ++ & - & + & - & + \\
\hline
\end{tabular}

NoTE: $\mathrm{P}=$ proband; age = present age/age at onset; $\mathrm{UMN}=$ upper motor neuron; $\mathrm{LMN}=$ lower motor neuron; - no disability; + mild disability; ++ ambulates with device; +++ wheel chair.

ing. Eventually, all patients showed gait, trunk, and limb ataxia, as well as pyramidal tract signs with increased reflexes and Babinski plantar responses. Myoclonic jerks were noted in all patients, but electroencephalography has shown no evidence of epilepsy. Fasciculations, impaired joint position sense, cerebellar dysarthria and mild pes cavus were uniform features. Nerve conduction studies showed findings consistent with axonal sensorimotor neuropathy, with evidence of active denervation in the distal muscles of the lower limbs. The optic fundi, visual fields, and corrected visual acuity were normal in all five patients.

The striking disturbance of eye movements was horizontal saccadic oscillations that were induced with each gaze shift (FIG. 1A). These oscillations about the position of the target showed inter-saccadic intervals (i.e., they were not flutter or opsoclonus, but macrosaccadic oscillations). Another abnormality was that the peak velocities of large, but not small, saccades were greater than $95 \%$ confidence limits for the control subjects (FIG. 1B). Patients 2 and 4 showed the greatest increase in saccadic velocities and these also showed the most frequent and largest saccadic oscillations with gaze shifts. There was no nystagmus in central or eccentric gaze, and smooth-pursuit and vestibular eye movements were normal.

We found a very consistent clinical picture in five sibs with SCA that has not yet been genetically identified. The pattern of inheritance suggests an autosomal recessive mode of inheritance. Although Friedreich's ataxia may cause a similar presentation, with saccadic intrusions, ${ }^{5}$ this was excluded by genetic testing. Other forms of SCA that can be currently tested were also excluded, although the clinical picture - and especially the disorder of eye movements - is not typical for any of them. Linkage studies are proceeding, and should make it possible to determine whether any other families with the same defect have a similar phenotype.

Saccadic oscillations about the point of fixation following a gaze shift are a feature of midline cerebellar lesions (or experimental inactivation) involving the fastigial nucleus. 2,6 These macrosaccadic oscillations should be differentiated from opsoclonus and flutter, which consists of bursts of oscillations without an intersaccadic interval. ${ }^{2}$ Flutter was absent in our patients, even when we tried to induce it using the combined saccadic-vergence movements. ${ }^{4}$ A novel finding was increased speed of large saccades (FIG. 1B). This finding was most evident in the two patients with most marked macrosaccadic oscillations, suggesting that an increased gain of the saccadic system (due to fastigial nucleus dysfunction) was the cause of the oscil- 
A

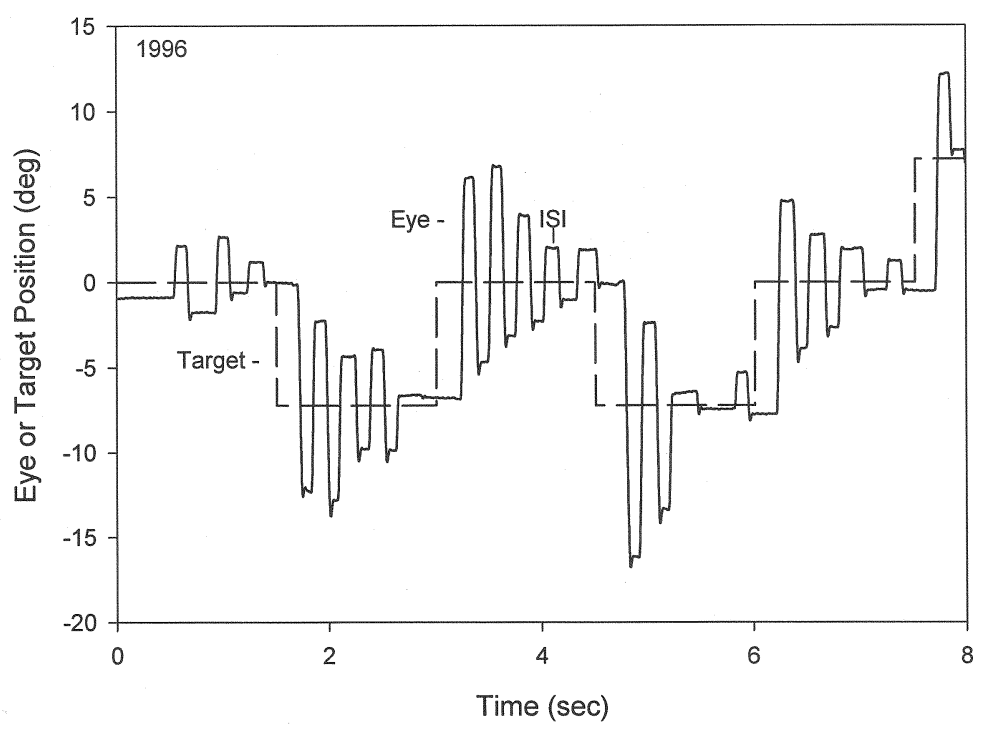

B

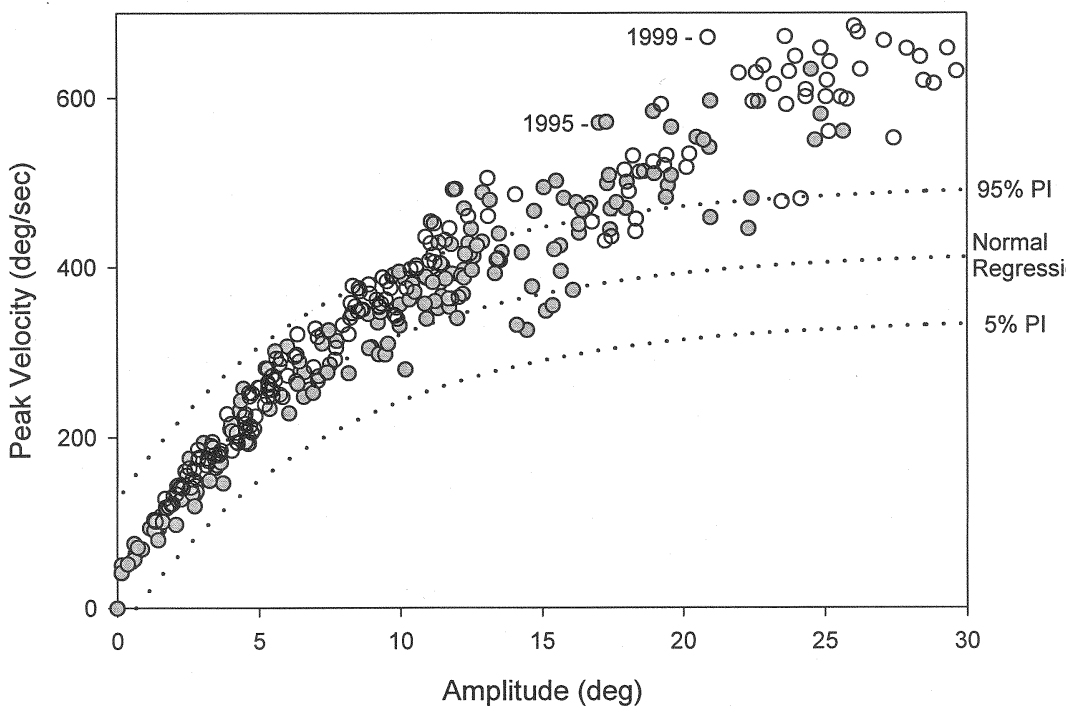

FIGURE 1. (A) Representative record of horizontal eye position from Patient 4, showing frequent, large saccadic intrusions during tracking of a stepping visual target; upward deflections indicate rightward movements. (B) Amplitude-peak velocity plot of horizontal saccades from Patient 4 during two sessions. Note that large saccades exceeded the $95 \%$ confidence interval for normal subjects. 
lations. Remarkably, no other abnormalities of eye movements, such as nystagmus or impaired smooth pursuit that are common with vestibular cerebellar disease, ${ }^{2}$ were present in our patients. The specificity of the disturbance of eye movements suggests a very restricted form of involvement of the cerebellum that affects the cells of the midline deep cerebellar nuclei.

\section{ACKNOWLEDGMENTS}

This work was supported by NIH Grant EY06717, the Department of Veterans Affairs, and the Armington Fund. We are grateful to Dr. Arthur Zinn for genetic advice, Dr. Eugene Dulaney for electromyography, and Drs. Lea Averbuch-Heller and Robert N. Sawyer, Jr. for assisting with evaluation of patients.

\section{REFERENCES}

1. Evidente, V.G.H. et al. 2000. Hereditary ataxias. Mayo Clin. Proc. 75: 475-490.

2. Leigh, R.J. \& D.S. ZeE. 1999. The Neurology of Eye Movements, 3rd ed. Oxford University Press. New York.

3. RotтACH, K.G. et al. 1996. Dynamic properties of horizontal and vertical eye movements in parkinsonian syndromes. Ann. Neurol. 36: 129-141

4. Ramat, S. et al. 1999. Conjugate ocular oscillations during shifts of the direction and depth of visual fixation. Invest. Ophthalmol. Visual Sci. 40:1681-1686.

5. SPIEKER, S. et al. 1995. Fixation instability and oculomotor abnormalities in Friedreich's ataxia. J. Neurol. 242: 517-521.

6. Robinson, F.R., A. Straube \& A.F. Fuchs. 1993. Role of the caudal fastigial nucleus in saccade generation. II. Effects of muscimol inactivation. J. Neurophysiol. 70: $1741-1758$. 